\title{
Neuroprotective effect of polysaccharides from Gastrodia elata Blume against corticosterone-induced apoptosis in PC12 cells via inhibition of the endoplasmic reticulum stress-mediated pathway
}

\author{
BENHONG ZHOU ${ }^{1,2}$, JUN TAN ${ }^{2}$, CHAN ZHANG $^{2}$ and YUE WU ${ }^{1}$ \\ ${ }^{1}$ Department of Pharmacy, Renmin Hospital of Wuhan University, Wuhan, Hubei 430060; \\ ${ }^{2}$ School of Pharmaceutical Sciences, Wuhan University, Wuhan, Hubei 430071, P.R. China
}

Received April 25, 2017; Accepted September 18, 2017

DOI: $10.3892 / \mathrm{mmr} .2017 .7948$

\begin{abstract}
Depression is a common mental health disorder and is the leading cause of disability worldwide. Gastrodia elata (G. elata) was demonstrated to exhibit a neuroprotective effect in the authors' previous study. The present study investigated the effect of polysaccharides from G. elata (GEP) on PC12 cell apoptosis induced by corticosterone (CORT) and its possible underlying mechanisms. PC12 cells were treated with $200 \mu \mathrm{M}$ CORT in the absence or presence of different concentrations of GEP for $48 \mathrm{~h}$. Then, cell viability was measured by CCK-8 assay. The lactate dehydrogenase (LDH) leakage was quantified using an LDH assay kit. The apoptosis degree of the PC12 cells and the morphology was measured by DAPI staining. Subsequently, intracellular ROS level was detected by using DCFH-DA method, the morphology staining of the endoplasmic reticulum in PC12 cells was determined using the cationic probe, and levels of five proteins involved in apoptosis, i.e., glucose-regulated protein, 78k Da (GRP78), $\mathrm{X}$-box binding protein 1 (XBP-1), growth arrest- and DNA damage-inducible gene 153 (GADD153), caspase 9 and caspase 12 were determined by western blotting. The results demonstrated that treatment with $1,000 \mu \mathrm{g} / \mathrm{ml}$ GEP prior to $200 \mu \mathrm{M}$ CORT exposure significantly protected the PC12 cells from CORT-induced cell apoptosis, and reduced levels of LDH leakage and intracellular reactive oxygen species. In addition, pretreatment with GEP inhibited the activation of GRP78, X-BP-1, GADD153, caspase 9 and caspase 12. These findings suggested that GEP exhibited a neuroprotective effect against CORT-induced apoptosis in PC12 cells, and the underlying molecular mechanisms were dependent on inhibition of the endoplasmic reticulum stress-mediated pathway. This
\end{abstract}

Correspondence to: Professor Benhong Zhou, Department of Pharmacy, Renmin Hospital of Wuhan University, 238 Jiefang Road, Wuhan, Hubei 430060, P.R. China

E-mail: benhongzh@whu.edu.cn

Key words: major depressive disorder, neuroprotective, Gastrodia elata Blume, polysaccharides provides novel insight into the effect of GEP when used for the treatment of diseases of the nervous system.

\section{Introduction}

Depression, is a mental health disorder characterized by pervasive and persistent low mood, frequently occurring alongside self-abasement and loss of interest in social contact, which can adversely affect an individuals normal life (1-3). Globally, $>300,000,000$ individuals of all ages suffer from depression (4). Depression is a major contributor to the overall global burden of diseases. However, owing to its unknown pathogenesis and complex pathogenic factors, the therapeutic efficacy of the classical antidepressants used in clinical practice to treat depression is not ideal. Therefore, novel antidepressants with the desired effect and superior levels of toleration are required.

Gastrodia elata (G. elata), known as 'Tian Ma' in Chinese, is a saprophytic perennial herb, which is widely used in traditional Chinese medicine and cuisine. Medically, it has been used to treat a variety of nervous and cerebrovascular diseases, including headache, dizziness, tetanus and epilepsy (5). In neurological investigations, gastrodin, one of major active components of G. elata, was reported to have a protective effect against 1-methyl-4-phenylpyridinium-induced cytotoxicity in human dopaminergic SH-SY5Y cells (6). The polysaccharides of G. elata (GEP), as the major active components in G. elata (7), have been demonstrated to exert several pharmacological effects, including reducing hypertension and improving serum lipid levels (8), and exhibiting anti-dengue virus bioactivities (9). In addition, the extraction rate of GEP reached $\sim 8.58 \%$ in our previous experiment, and the antidepressant-like activity of a $G$. elata ethanol extract in mice was observed (10). Although current understanding of how polysaccharides isolated from $G$. elata may exert a pharmacological neuroprotective effect, investigations on the neuroprotective effects and underlying mechanism of GEP have been limited.

PC12 cells, a cell line with typical neuron characteristics and which generates a high level of glucocorticoid receptors, have been used as a useful model to simulate the state of glucocorticoid damage on hippocampal neurons when treated with high concentrations of corticosterone (CORT) (11). In addition, 
CORT is the major rodent glucocorticoid, and exposure to continued high CORT concentrations can cause lymphocyte, cortex and hippocampal nerve cell damage (12), which can be reversed by antidepressants. There is also sufficient evidence to suggest that a drug possessing the ability to reverse CORT-induced neurotoxicity may have a possible therapeutic potential in preventing or treating major depression (13).

In previous years, several experimental and clinical data have provided support for the hypothesis that dysregulation of the hypothalamus-pituitary-adrenal (HPA) axis is involved in the pathogenesis of depression $(14,15)$. It is usually acknowledged that the HPA axis is activated in response to stress, which results in the increased concentrations of glucocorticoids in the circulating blood (16).

Multiple molecular mechanisms are involved in CORT-induced cell apoptosis, including the mitochondrial apoptotic pathway (17), extracellular signal-regulated kinase (ERK)1/2 pathway (18), phosphoinositide 3-kinase (PI3K)/Akt signaling pathway $(19,20)$ and endoplasmic reticulum $(\mathrm{ER})$ stress-mediated pathway (21). Additionally, on the basis of our previous study, the incubation of PC12 cells with CORT significantly upregulated $\left[\mathrm{Ca}^{2+}\right]$ concentrations (22), which were bound up with the apoptotic signals generated at the ER (23).

Oxidative stress is a hallmark of various neuropathological disorders, and the underlying mechanism in several neurodegenerative diseases and brain injuries, including Parkinson's disease (24), Alzheimer's disease (25,26), autism (27), chronic fatigue syndrome (28) and depression (29). Oxidative stress can cause base damage, which is predominantly indirect, and can cause strand breaks in DNA (30). Persistent oxidative stress leads to reactive oxygen species (ROS) and reactive nitrogen species (RNS) formation. ROS and RNS exacerbate oxidative stress by attacking organelles, including mitochondria (31).

ER is a multifunctional organelle and is a requisite in all cells, which can perform protein folding and calcium storage. As cells maintain homeostasis, when cellular homeostasis has been disrupted, a series of signaling pathways are activated to rebalance the cellular biochemical processes. Among all signaling pathways, unfolded proteins cause an unfolded protein response (UPR) as a stress response in the ER, which is also known as ER stress (32).

In the present study, the neuroprotective effect of GEP against CORT-induced apoptosis was evaluated in PC12 cells, which possess typical neuron characteristics with high expression levels of glucocorticoid receptors, and discussed whether the neuroprotective effects of GEP were via inhibiting the oxidative stress and ER stress-mediated pathway.

\section{Materials and methods}

Plant materials. G. elata was collected from Anqing (Anhui, China). The plants were identified by Professor Hong Zhang of Renmin Hospital of Wuhan University (Wuhan, China). A voucher specimen (no. 1406906) was deposited in the herbarium of the Institute of Botany, Chinese Academy of Sciences (Beijing, China). The plant material was dried in the open air and retained for use.

Chemicals and reagents. The following were used in the present study: Rat PC12 adrenal gland tumor cell line (Cell Resource
Center, Shanghai Institutes for Biological Sciences, Shanghai, China), Cell Counting Kit-8 (CCK-8; Dojindo Corporation, Kumamoto Japan); DMEM (Hyclone; GE Healthcare Life Sciences, Logan, UT, USA; cat. no. SH30022.01); penicillin and streptomycin (Gibco; Thermo Fisher Scientific, Inc; cat. no. 15140-122); fetal bovine serum (FBS; Gibco; Thermo Fisher Scientific,Inc; cat.no.10099-141);CORT(Sigma-Aldrich;Merck Millipore, Darmstadt, Germany; cat. no. C2505-500MG); LDH assay kit (Nanjing Jiancheng Biological Engineering Research Center, Nanjing, China); Hoechst 33258 (Beyotime Institute of Biotechnology, Haimen, China; cat. no. C0003-2); DCFH-DA (Sigma-Aldrich; Merck Millipore; cat. no. D6883/50 mg); Antibodies against GRP78, glucose-regulated protein, $78 \mathrm{kDa}$ (GRP78; Abcam, Cambridge, UK; cat. no. ab108613), X-box binding protein 1 (XBP1; Abcam; cat. no. ab37152), growth arrest- and DNA damage-inducible gene 153 (GADD153; BIOSS, Beijing, China; cat. no. bs-8875R), GAPDH (Abcam; cat. no. ab37168), caspase 12 (BIOSS; cat. no. bs1105R) and caspase 9 (ProteinTech Group, Inc., Chicago, IL, USA; cat. no. 10380-1-ap); and horseradish peroxidase (HRP)-goat anti rabbit immunoglobulin G (KPL, Inc. Gaithersburg, MD, USA; cat. no. 074-1506). All other reagents used were of analytical grade.

Isolation and purification of GEP. GEP was prepared as follows: $100 \mathrm{~g}$ dry G. elata tuber powder was extracted for $1 \mathrm{~h}$ three times with $95 \%$ ethanol at $70^{\circ} \mathrm{C}$. The extract was filtered using filter paper and the filtrate discarded. The filtered residue was immersed in water at a ratio of 1:30, and extraction was performed for $1 \mathrm{~h}$ three times in a water bath at $60^{\circ} \mathrm{C}$. The filtrate was then collected and concentrated to $200 \mathrm{ml}$ as the final volume, following which it was precipitated with $600 \mathrm{ml}$ of $95 \%$ ethanol (concentrated solution: $95 \%$ ethanol; 1:3). The precipitate was dissolved in $100 \mathrm{ml}$ of water and deproteinized 7-8 times with Sevag reagent (chloroform: n-butanol; 5:1) until no protein was detected using an ultraviolet spectrophotometer. Following dialysis (molecular weight cut-off $1.0 \mathrm{kDa}$ ) against water for $24 \mathrm{~h}$ and lyophilization, crude polysaccharide was obtained. The yield of GEP was $8.58 \%$ (w/w). The purity of the crude polysaccharide was $97 \%$.

The crude polysaccharide was dissolved in distilled water at a concentration of $10 \mathrm{mg} / \mathrm{ml}$ and then fractionated using a Sephadex G-75 column $(3.5 \times 75 \mathrm{~cm})$. Elution was performed with $0.15 \mathrm{M} \mathrm{NaCl}$ at a flow rate of $1 \mathrm{ml} / \mathrm{min}$. The polysaccharide elution profile was determined using the phenol-sulfuric acid method, and the fractions (test tube nos. 40-53) containing polysaccharide were lyophilized to obtain the purified polysaccharide, referred to as $\operatorname{GEP}(33,34)$.

Cell culture and treatment. The PC12 cells were maintained in DMEM supplemented with penicillin (100 U/ml), streptomycin $(100 \mu \mathrm{g} / \mathrm{ml})$ and $10 \%$ FBS in a humidified atmosphere of $95 \%$ air and $5 \% \mathrm{CO}_{2}$ at $37^{\circ} \mathrm{C}$.

For all experiments, cells in the exponential phase of growth were used. CORT was dissolved in dimethyl sulphoxide, which had a final concentration of $<0.1 \%(\mathrm{v} / \mathrm{v})$. All manipulations were run in three duplicates for each treatment group in the experiment.

To examine the neuroprotective effect of GEP, the appropriate concentration of CORT was selected on the basis of 
Fig. 1B. A dose of $200 \mu \mathrm{mol} / \mathrm{l} \mathrm{CORT}$ was selected to induce PC12 cell apoptosis. The PC12 cells were divided into the following groups: Control group; CORT (200 $\mu \mathrm{mol} / \mathrm{l})$ group; and CORT $(200 \mu \mathrm{mol} / \mathrm{l})+\operatorname{GEP}(250,500$ and $1,000 \mu \mathrm{g} / \mathrm{ml})$ groups. For the CORT+GEP groups, GEP was added to the PC12 cells for 30 min prior to treatment with CORT. In all experiments, with the exception of the control group, CORT was applied $48 \mathrm{~h}$ following treatment with GEP.

Measurement of cell viability. The PC12 cells were seeded in a 96-well culture plate at $1 \times 10^{5}$ cells $/ \mathrm{ml}$. The cell viability was quantified using a CCK-8 kit according to the manufacturer's protocol. Briefly, $10 \mu \mathrm{l}$ of CCK- 8 solution $(5 \mathrm{mg} / \mathrm{ml})$ was added to each well of a 96 -well plate and incubated for $1.5 \mathrm{~h}$ at $37^{\circ} \mathrm{C}$ in the dark. The optical density value was measured at an absorption wavelength of $450 \mathrm{~nm}$ on a microplate reader. Cell viability is expressed as a percentage of the untreated control group.

Measurement of $L D H$ release. The cytotoxicity was determined by the release of LDH using a diagnostic kit according to the manufacturer's protocol. Briefly, following treatment, $2 \mathrm{ml}$ of the culture supernatant in a 6-well plate was collected from each well and centrifuged at $1,000 \mathrm{xg}$ for $5 \mathrm{~min}$ at $4^{\circ} \mathrm{C}$; following which another $2 \mathrm{ml}$ culture was added into each well, and the cells crushed by ultrasound to free the LDH in the cells. The absorbance of each of the samples was measured at $490 \mathrm{~nm}$ with a microplate reader, and background absorbance from the culture medium, which was not used for any cell cultures, was subtracted from all absorbance measurements. Each experiment was performed three times. LDH release was defined as the ratio of LDH in the media to total LDH (LDH in the media and LDH in the cell) according to the following equation: $\mathrm{LDH}$ release $(\%)=(\mathrm{LDH}$ activity in the media/total LDH activity) x $100 \%$.

Measurement of intracellular ROS levels. ROS levels were measured using the DCFH-DA method. DCFH-DA is a non-fluorescent compound. It can be enzymatically converted to a highly fluorescent compound, DCF, in the presence of ROS. In brief, following treatment, the cells were washed with phosphate-buffered saline (PBS) and incubated with DCFH-DA at a final concentration of $10 \mu \mathrm{mol} / 1$ for $30 \mathrm{~min}$ at $37^{\circ} \mathrm{C}$ in the dark. The fluorescence intensity was measured in a microplate reader at an excitation wavelength of $485 \mathrm{~nm}$ and an emission wavelength of $535 \mathrm{~nm}$, following washing of the cells three times with PBS to remove extracellular DCFH-DA and adjustment of the cell number in the different groups consistently. The level of intracellular ROS was calculated as a percentage of that in the untreated control.

Assessment with Hoechst 33258 staining. Hoechst 33258 staining, which distinguishes apoptotic cells from normal cells based on nuclear chromatin condensation and fragmentation, was used for the qualitative and quantitative analyses of apoptotic cells in the present study. Following treatment, the cells on slides were fixed in stain-fixative overnight at $4^{\circ} \mathrm{C}$. The slides were then washed twice with PBS to remove the extra stain-fixative, following which the slides were incubated with $5 \mu \mathrm{g} / \mathrm{ml}$ Hoechst 33342 for $10 \mathrm{~min}$, and then washed twice with PBS. Finally, the staining was visualized and images were
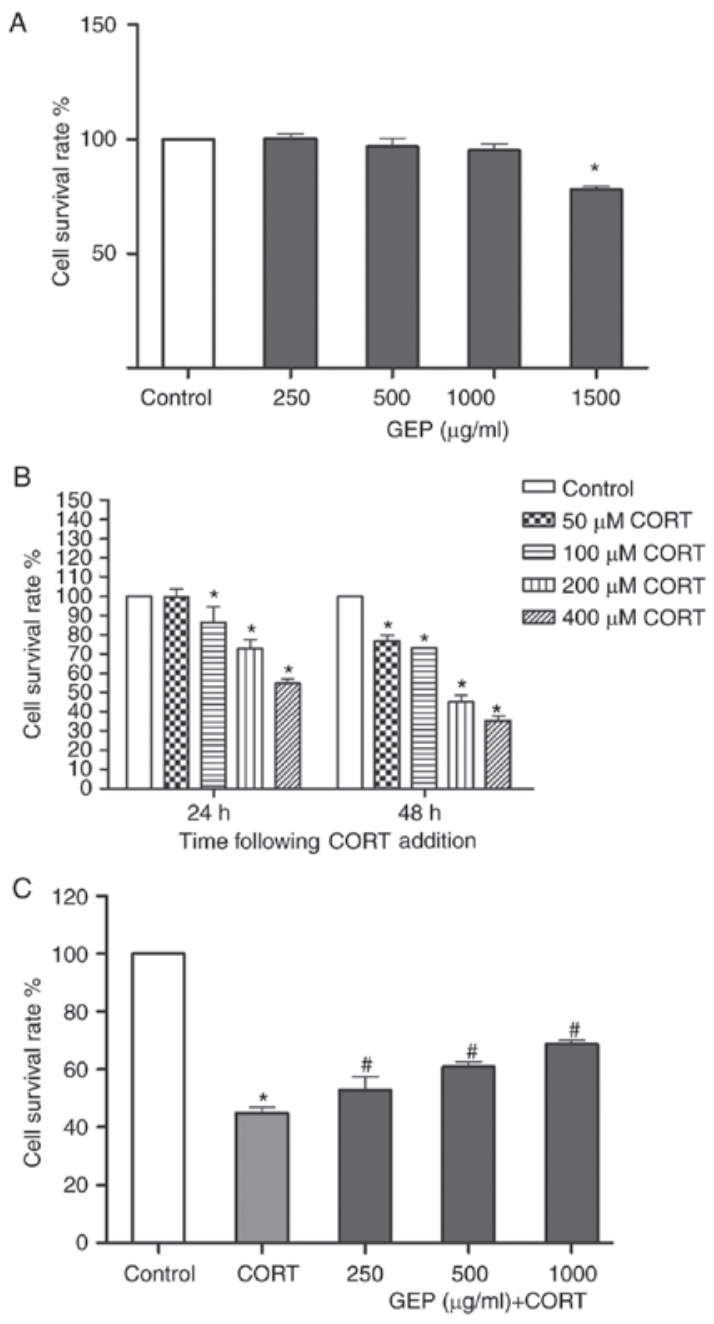

Figure 1. Cell Counting Kit-8 assay of the effect of GEP and CORT on PC12 cell viability. (A) Viability of cells treated with GEP. (B) Viability of cells treated with CORT. (C) Viability of cells treated with CORT and with GEP+CORT. Results are presented as the mean \pm standard deviation of three individual experiments $(\mathrm{n}=3) ;{ }^{*} \mathrm{P}<0.05$, compared with the control group; ${ }^{\#} \mathrm{P}<0.05$, compared with the CORT group. CORT, corticosterone; GEP, polysaccharides from Gastrodia elata.

captured using fluorescence microscopy. All the procedures were performed in the dark. The apoptotic nuclei were counted in at least 400 cells from three non-overlapping fields in each group, and expressed as a percentage of the total number of nuclei counted: Rate of apoptosis $(\%)=$ apoptotic cells/total cells x $100 \%$.

ER morphology staining. The morphological staining of the ER in the PC12 cells was determined using the cationic probe, 3,3-dihexyloxacarbocyanine iodide, which can selectively accumulate together in the ER and present with green fluorescence $(35,36)$. The PC12 cells were cultured in a 6 -well plate and, at the end of treatment, the cells were washed with PBS three times, prior to being loaded with a carbocyanine staining solution of DiOC6 (3) at $37^{\circ} \mathrm{C}$ for $15 \mathrm{~min}$. Images were captured using a fluorescence microscope with excitation and emission wavelengths of 488 and $505 \mathrm{~nm}$, respectively.

Western blot analysis. The PC12 cells were cultured in 6-well plates and treatments were performed as described above, 
A

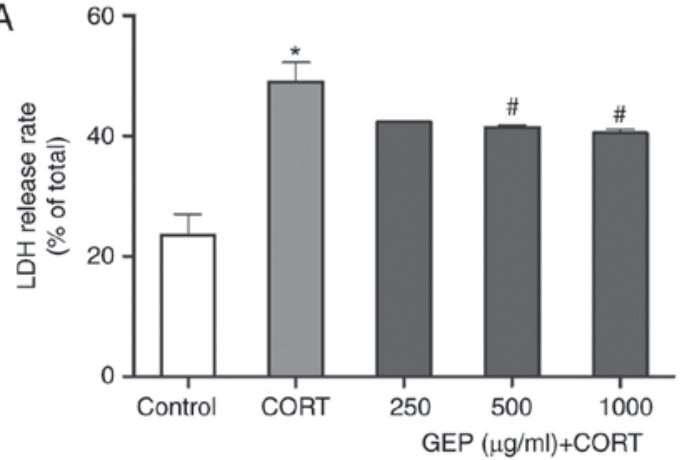

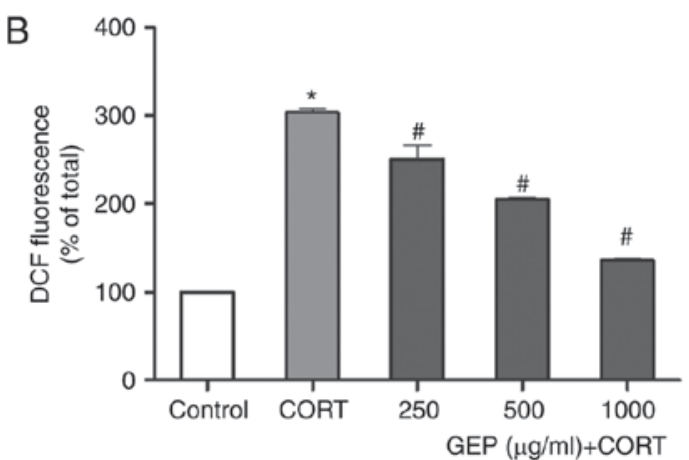

Figure 2. Effect of GEP on LDH leakage and the level of ROS in CORT-induced PC12 cells. (A) Effect of GEP on LDH leakage. (B) Effect of GEP on ROS levels. Results are presented as the mean \pm standard deviation $(n=3) ;{ }^{*} \mathrm{P}<0.05$, compared with the control group; ${ }^{*} \mathrm{P}<0.05$, compared with the CORT group. CORT, corticosterone; GEP, polysaccharides from Gastrodia elata; LDH, lactate dehydrogenase; ROS, reactive oxygen species.

following which the cells were harvested, washed once with PBS, and then lysed with cell lysis buffer containing $1 \%$ phenylmethylsulfonyl fluoride for $30 \mathrm{~min}$ at $4^{\circ} \mathrm{C}$, followed by centrifugation at $2,000 \mathrm{x}$ g for $5 \mathrm{~min}$ at $4^{\circ} \mathrm{C}$. The concentration of protein was determined using a bicinchoninic acid protein assay. Equal quantities of protein $(40 \mu \mathrm{g})$ were separated by electrophoresis with $15 \%$ sodium dodecyl sulfate polyacrylamide gels, followed by transfer onto nitrocellulose membranes. These membranes were incubated with 5\% (w/v) non-fat milk powder in Tris-buffered saline containing $0.1 \%$ (v/v) Triton $\mathrm{X}-100$ (TBST) for $1 \mathrm{~h}$ to block nonspecific binding sites. The membranes were then incubated overnight at $4^{\circ} \mathrm{C}$ with the one of the following primary antibodies: Rabbit anti-GRP78 $(1: 1,000)$, rabbit anti-XBP-1 $(1: 1,000)$, rabbit anti-GADD153 $(1: 1,000)$, rabbit anti-caspase $9(1: 1,000)$ or rabbit anti-caspase $12(1: 1,000)$. Following washing three times with TBST, the membranes were incubated for $30 \mathrm{~min}$ at room temperature in the dark with the HRP-goat anti rabbit secondary antibodies $(1: 10,000)$. Following rewashing four times with TBST, the membranes were developed using enhanced chemiluminescence. Each independent experiment was performed three times. Western blot analysis was performed using AlphaEaseFC V.4 Software (ProteinSimple, San Jose, USA). Values were normalized to corresponding levels of GADPH and expressed as a percentage of the control value. The results are presented as the mean \pm standard deviation.

Statistical analysis. Data were analyzed using SPSS version 17.0 software (SPSS, Inc., Chicago, IL, USA). Differences between groups were compared using one-way analysis of variance and the least significant difference test to determine whether the results were statistically significant. $\mathrm{P} \leq 0.05$ was considered to indicate a statistically significant difference. All results are expressed as the mean \pm standard deviation.

\section{Results}

Effect of GEP on PC12 cell viability determined using a CCK-8 assay. The viability of the $\mathrm{PC} 12$ cells following exposure to GEP and CORT was determined using a CCK-8 assay. As shown in Fig. 1A, no significant changes were observed in the viability of cells treated with individual GEP at concentrations of 250,500 and $1,000 \mu \mathrm{g} / \mathrm{ml}$, whereas $1,500 \mu \mathrm{g} / \mathrm{ml}$ led to visible cell damage. Therefore, $250-1,000 \mu \mathrm{g} / \mathrm{ml}$ of GEP was selected for the subsequent experiments.

CORT gradually reduced cell viability as the concentration and treatment time increased (Fig. 1B). When treated with $200 \mu \mathrm{M}$ CORT for $48 \mathrm{~h}$, cell viability decreased to $44.95 \pm 3.64 \%$, therefore this concentration was used in the subsequent experiments.

Effect of GEP on CORT-induced PC12 cell viability determined using a CCK- 8 assay. The viability of PC12 cells following exposure to CORT was determined using a CCK-8 assay. As shown in Fig. 1C, stimulation with $200 \mu \mathrm{M}$ CORT alone resulted in a significant decrease in cell viability, compared with that in the control group. However, pretreatment with GEP at various concentrations $(250,500$ and $1,000 \mu \mathrm{g} / \mathrm{ml})$ in the presence of CORT led to a significant increase in cell survival rates to $53.05 \pm 7.76,60.83 \pm 3.53$ and $68.73 \pm 2.24 \%$, respectively. These results demonstrated that GEP alleviate the toxic effect of CORT on PC12 cells.

Effect of GEP on CORT-induced LDH leakage in PC12 cells. An LDH assay was performed to investigate damage to cell membranes following CORT treatment. As shown in Fig. 2A, compared with control group, an increase in the level of LDH release was observed in the CORT-treated group $(\mathrm{P}<0.05)$. By contrast, pretreatment with GEP alleviated this effect, and the percentages of LDH release in the groups treated with 250,500 and $1,000 \mu \mathrm{g} / \mathrm{ml}$ GEP were $42.33 \pm 0.04,41.37 \pm 0.66$ and $40.46 \pm 1.16 \%$ respectively. The $250 \mu \mathrm{g} / \mathrm{ml}$ pretreatment concentration reduced the release but without statistical significance. These data further indicated that GEP had a protective effect towards CORT-damaged PC12 cells. However, this method measures necrosis, which can occur in vitro sequentially to the induction of apoptosis or as a primary event (37). The results of the present study showed that GEP alleviated the increase in LDH levels with minimal difference between each dose. According to literature, the release of the cytosolic LDH enzyme is used to evaluate membrane integrity, thereby indicating cell death by necrosis (38). Therefore, it was suggested that the protective effect of GEP on PC12 cell membrane integrity was limited. 
A

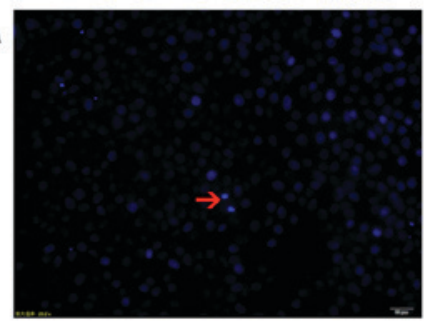

$\mathrm{B}$

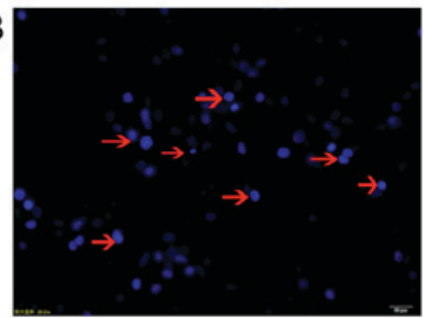

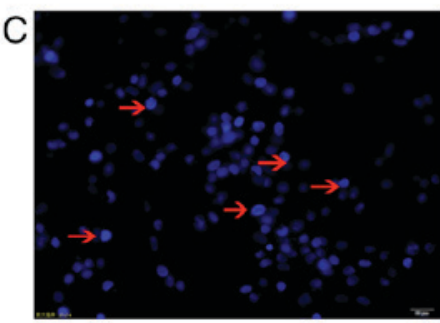
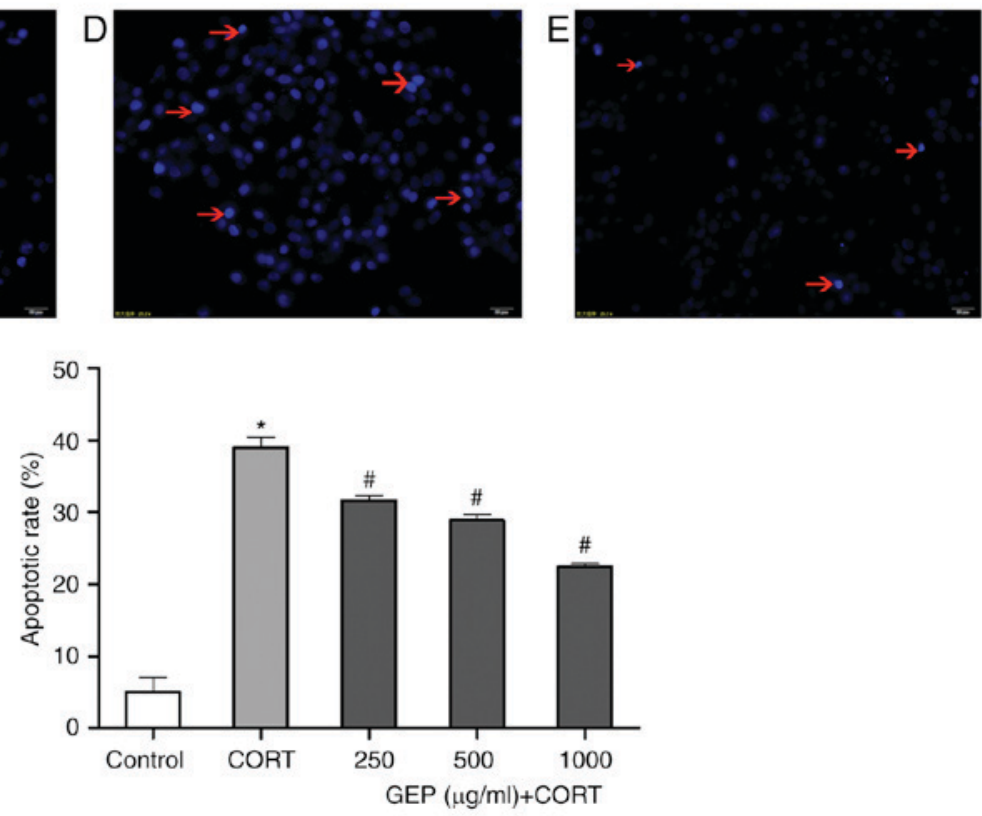

Figure 3. Effect of GEP on cell apoptosis in CORT-induced PC12 cells. Cells were exposed to $200 \mu \mathrm{M}$ of CORT in the absence or presence of GEP for $48 \mathrm{~h}$. Following treatment, apoptotic PC12 cells were visualized using Hoechst 33342 staining. (A) Control group; cells treated with (B) $200 \mu \mathrm{M}$ CORT; (C) $200 \mu \mathrm{M}$ CORT $+250 \mu \mathrm{g} / \mathrm{ml} \mathrm{GEP}$; (D) $200 \mu \mathrm{M}$ CORT+500 $\mu \mathrm{g} / \mathrm{ml} \mathrm{GEP}$; and (E) $200 \mu \mathrm{M}$ CORT+1,000 $\mu \mathrm{g} / \mathrm{ml}$ GEP. The red arrows indicate apoptotic PC12 cells and magnification, $\mathrm{x} 400$. Results are presented as the mean \pm standard deviation $(\mathrm{n}=3)$. ${ }^{*} \mathrm{P}<0.05$, compared with the control group; ${ }^{*} \mathrm{P}<0.05$, compared with the CORT group. CORT, corticosterone; GEP, polysaccharides from Gastrodia elata.

Measurement of intracellular ROS levels. As shown in Fig. 2B, the intracellular level of ROS in the CORT-treated group markedly increased to $304.30 \pm 6.72 \%$ of the control, which suggested that CORT induced oxidative stress. When the cells were pretreated with different concentrations of GEP $(250,500$ and $1,000 \mu \mathrm{g} / \mathrm{ml})$ in the presence of $200 \mu \mathrm{M}$ CORT for $48 \mathrm{~h}$, the level reduced significantly to $250.82 \pm 26.83$, $205.60 \pm 2.41$ and $136.13 \pm 3.37 \%$, respectively.

Effect of GEP on CORT-induced apoptosis in PC12 cells, determined using Hoechst 33258 staining. Hoechst 33258 is DNA-specific, and stains the condensed chromatin in apoptotic cells. Early apoptotic cells show an increased uptake of the vital DNA dye Hoechst 33342, compared with live cells due to changes in membrane permeability (39). As shown in Fig. 3A-E, normal PC12 cells had a uniform soft fluorescence, were light blue in color, and had round nuclei with sharp edges. Treatment with CORT for $48 \mathrm{~h}$ led to cells exhibiting typical characteristics of apoptosis, including small, bright nuclei with irregular margins and apparent fluorescent debris as indicated by the red arrows. However, with GEP pretreatment, the cell nuclei appeared similar to those in the control, suggesting that GEP reduced the apoptotic effect of CORT.

Compared with the control group, the percentage of apoptotic nuclei in the CORT-treated cells was significantly increased, with apoptosis increased to $38.98 \pm 2.52 \%(\mathrm{P}<0.05)$. However, pretreatment with GEP $(250,500$ and 1,000 $\mu \mathrm{g} / \mathrm{ml})$ reduced the apoptotic rates to $31.60 \pm 1.14,28.90 \pm 1.38$ and $22.51 \pm 0.67 \%$, respectively $(\mathrm{P}<0.05$; Fig. 3 ).

Effect of GEP on CORT-induced ER stress in PC12 cells. CORT treatment resulted in the reinforced assembling of 3,3-dihexyloxacarbocyanine iodide to the electronegative ER membrane to cause a significant increase in green fluorescence, compared with that in the control group (Fig. 4A-E). GEP pretreatment reduced the green fluorescence comparatively. The results revealed that GEP markedly alleviated the ER stress induced by CORT.

Effect of GEP on ER stress-associated proteins. In order to examine whether the CORT-induced apoptosis of PC12 cells is associated with ER stress, the present study analyzed the expression levels of GRP78, XBP-1, GADD153, caspase 9 and caspase 12, which are biomarkers of ER activation, using western blot analysis. As shown in Fig. 5A-E, the expression levels of GRP78, XBP-1, GADD153, caspase 9 and caspase 12 were significantly increased in the PC12 cells following incubation of the cells with $200 \mu \mathrm{M}$ CORT. However, the upregulation of these biomarkers was attenuated by GEP pretreatment in a concentration-dependent manner. 

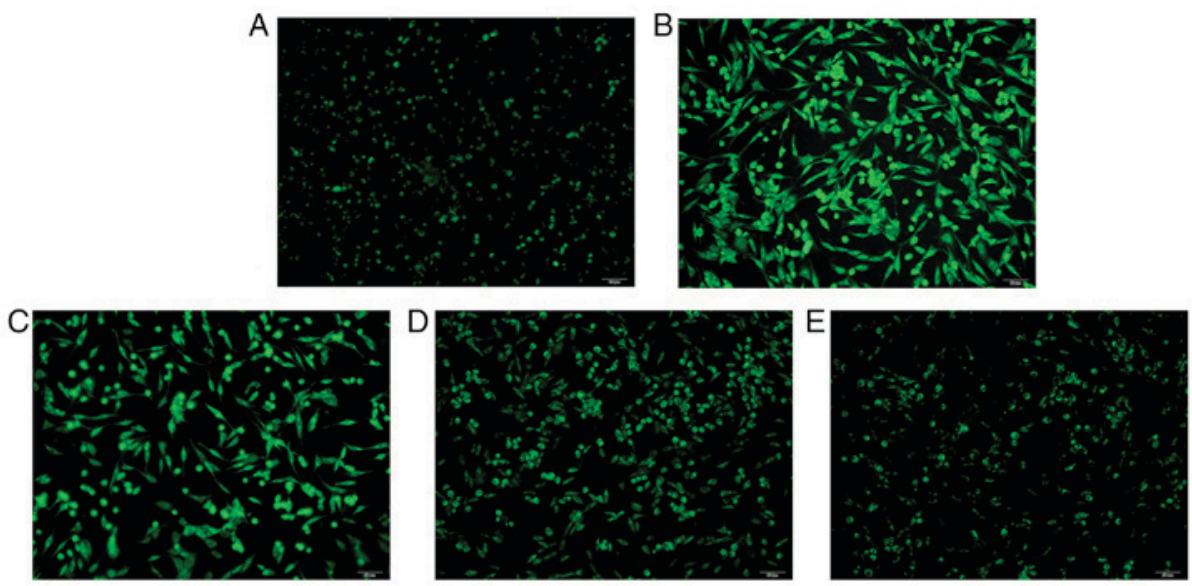

Figure 4. Effect of GEP on the morphology of ER stress in CORT-induced PC12 cells. Cells were exposed to $200 \mu \mathrm{M}$ of CORT in the absence or presence of GEP for $48 \mathrm{~h}$. Fluorescence intensity is representative of the degree of ER stress. (A) Control group; cells treated with (B) $200 \mu \mathrm{M} \mathrm{CORT}$; (C) $200 \mu \mathrm{M}$ CORT $+250 \mu \mathrm{g} / \mathrm{ml} \mathrm{GEP}$; (D) $200 \mu \mathrm{M}$ CORT+500 $\mu \mathrm{g} / \mathrm{ml}$ GEP; and (E) $200 \mu \mathrm{M}$ CORT+1,000 $\mu \mathrm{g} / \mathrm{ml}$ GEP. Magnification, x200. CORT, corticosterone. GEP, polysaccharides from Gastrodia elata; ER, endoplasmic reticulum.

\section{Discussion}

The present study demonstrated that GEP exerted a protective effect against CORT-induced apoptosis in PC12 cells, which was confirmed using a CCK-8 assay and LDH detection, and from evidence that the $\mathrm{PC} 12$ cells underwent conformational changes through morphological observation and Hoechst 33258 staining. Therefore, GEP may offer potential to as a novel therapeutic agent in the treatment of depression.

In the present study, PC12 cells were used to establish a model of depression. The PC12 cell line has typical neuron characteristics and generates a high level of glucocorticoid receptors. Several other cell lines were also suitable for use; for example, SH-SY5Y, C6 and BV2 cell lines. The use of in vivo models of depression is also required in the future.

Based on previous studies, the association between ROS generation and cellular antioxidant systems determines whether cells are ultimately damaged, despite ROS being found in all living cells (40). A number of previous studies suggested that glucocorticoid treatment had a negative effect on the survival of hippocampal cultures during oxidative stress, which was caused by generating superfluous ROS (41). Mitochondrial ROS induce the activation of a large number of mitochondrial apoptotic proteins, leading to cell apoptosis and death (42). In the nervous system, apoptosis can be activated in certain physiological and pathological conditions, and apoptotic cells have been found in the hippocampus of patients with depression (43). Therefore, apoptosis in hippocampal neurons may be one of the pathogenetic factors involved in clinical depression. The results of the present study indicated that the PC12 cells treated with CORT generated excessive ROS combined with an increased apoptotic rate. However, GEP significantly reversed this effect by lowering the level of ROS.

ER stress has been demonstrated to be a significant potential connection between high levels of ROS and cell apoptosis. On the basis of our previous study, the incubation of PC12 cells with CORT was found to upregulate $\left[\mathrm{Ca}^{2+}\right]$ concentrations significantly (22), which was bound up with apoptotic signals generated at the ER (23). It was also found that the upregulated concentration of $\left[\mathrm{Ca}^{2+}\right]$ was reduced by treatment with GEP (22). In addition, alterations of intra-ER $\mathrm{Ca}^{2+}$ led to the production of ER stress-induced ROS. In the present study, ER morphological staining revealed that treatment with CORT $(200 \mu \mathrm{M})$ caused a significant increase in green fluorescence, compared with that in the control group, which indicated that CORT likely induced the ER stress in the PC12 cells. It is known that DiOC6 (3) can be a useful fluorescent dye for staining the ER. It is a positively charged molecule, which permeates through the plasma membrane. At low concentrations, it accumulates in mitochondria due to their large negative membrane potential. At higher concentrations, the dye stains other membranes, including the ER. In the present study on ER stress, DiOC6 (3) was selected to determine whether ER stress was activated as a qualitative trail. Considering that DiOC5 (3) is not a fluorochrome aimed at the ER, this may be a limitation in the present study and therefore, it was validated using western blot analysis. GEP pretreatment reduced green fluorescence comparatively, which indicated that ER stress may be involved in the neuroprotective effect of GEP against CORT-induced apoptosis. Therefore, the expression of ER stress-related proteins were measured to elucidate the underlying mechanism.

The UPR is now a well-characterized signaling pathway. In the canonical model of the UPR, UPR signaling is initiated by three major sensing molecules: PKR-like ER kinase (PERK), inositol-requiring $1 \alpha$ (IRE1 $\alpha$ ), and activating transcription factor- $6 \alpha$ (ATF6 $\alpha$ ) (44). The activation of IRE1 $\alpha$ and ATF6 $\alpha$ can lead to the induction of chaperones, including GRP78, which increase protein-folding capacity; the activation of PERK leads to a reduction in protein production (45). In the course of this transfer, the activated IRE1 catalyzes the splicing of an unconventional intron from ubiquitously expressed XBP-1-unspliced, into the XBP-1-spliced isoform (46). The XBP-1-spliced isoform is a transcription factor, which increases the protein folding capacity of the ER and turnover of misfolded proteins by inducing ER-resident chaperones (45). Therefore, XBP-1-spliced is a key constituent of the UPR, which indicates that it is also a key constituent of ER stress. The continuous overproduction of XBP-1-spliced induces apoptosis (47). 

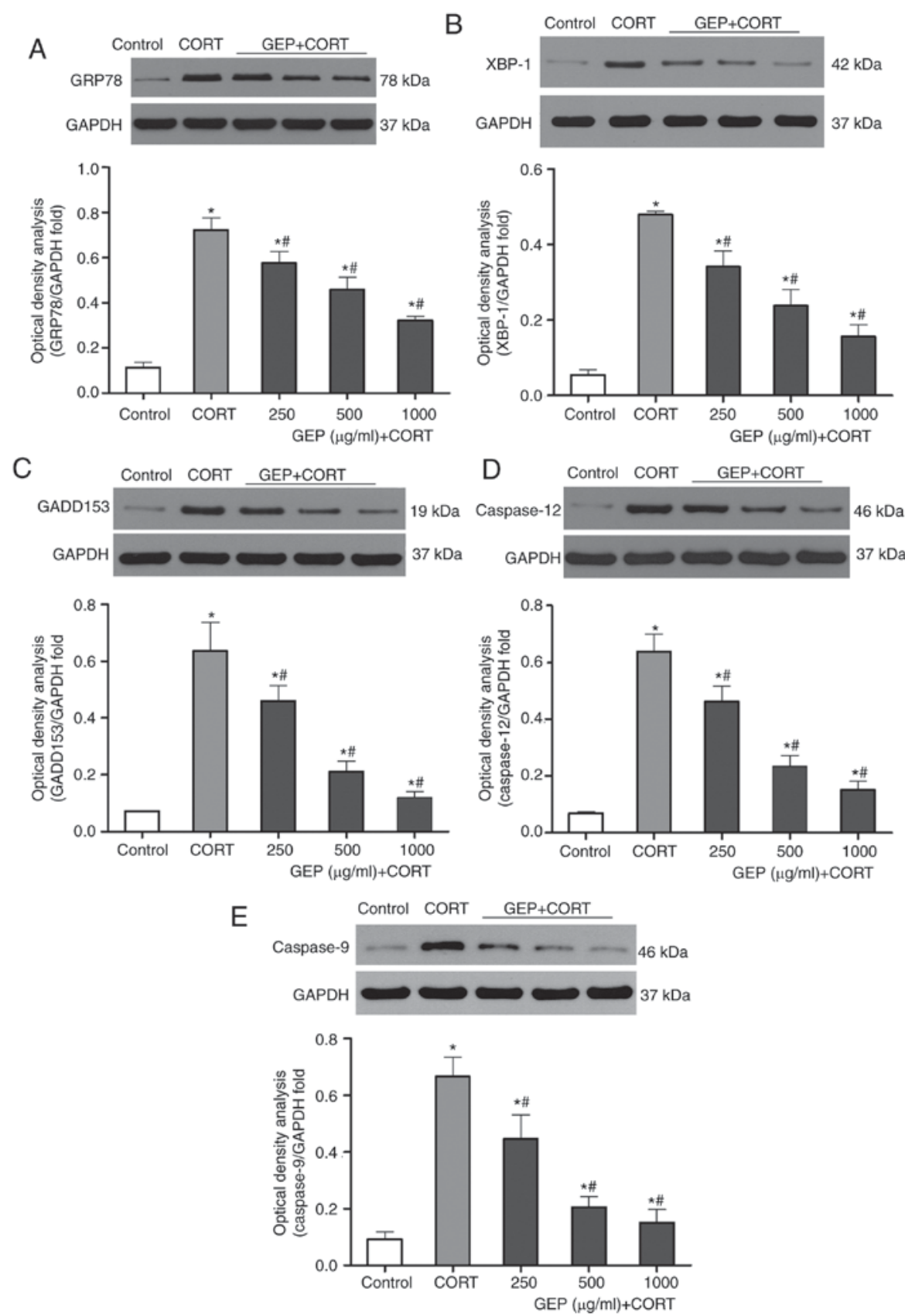

Figure 5. Effects of GEP on expression levels of GRP78, XBP-1, GADD153, caspase 12 and caspase 9 in CORT-treated PC12 cells. Expression levels were assessed using western blot analysis, with data presented as the mean \pm standard deviation $(\mathrm{n}=3)$. ${ }^{*} \mathrm{P}<0.05$, compared with the control group; ${ }^{*} \mathrm{P}<0.05$, compared with the CORT group. The groups comprised a control group, and groups of cells treated with $200 \mu \mathrm{M} \mathrm{CORT,} 200 \mu \mathrm{M} \mathrm{CORT}+250 \mu \mathrm{g} / \mathrm{ml}$ GEP, $200 \mu \mathrm{M}$ CORT $+500 \mu \mathrm{g} / \mathrm{ml} \mathrm{GEP}$, and $200 \mu \mathrm{M}$ CORT $+1,000 \mu \mathrm{g} / \mathrm{ml}$ GEP. Expression levels of (A) GRP78, (B) XBP-1, (C) GADD153, (D) caspase 12, and (E) caspase 9 were determined. All levels were relative to GAPDH. CORT, corticosterone; GEP, polysaccharides from Gastrodia elata; GRP78, glucose-regulated protein, 78 kDa; XBP-1, X-box binding protein 1; GADD153, growth arrest-and DNA damage-inducible gene 153.

C/EBP homologous protein (CHOP), also known as GADD153, is a transcription factor encoded by the DDIT3 gene (48), which has been confirmed as one of the highest inducible genes during ER stress by microarray studies. Accumulated evidence suggests that the overexpression of CHOP, which is also a downstream target of XBP-1, can lead to enhanced oxidant injury and apoptosis (49). An increased CHOP level is a significant mediator of ER stress-mediated cell death (50). In the present study, significantly increased levels of XBP-1 and GADD153 were found in the CORT-induced injury PC12 cells, which, as mentioned above, are major apoptotic factors. Combined with the results of ROS measurement and ER morphological staining, the results indicated that CORT induced PC12 cell apoptosis by activating ER stress.

As mentioned above, in the canonical model, the intraluminal domains of these initiators, namely the amino termini of IRE1 and PERK, and the carboxyl terminus of ATF6, are bound by the chaperone GRP78 in the absence of stress and are rendered inactive $(50,51)$. Following the activation of ER stress, it has been shown that the expression level of GRP78 is significantly enhanced $(53,53)$. GRP78 is an abundant ER chaperone, which is crucial for ER function, acting as a master 
modulator of the UPR. In the present study, in addition to the significant PC12 cell apoptosis induced by CORT, the expression level of GRP78 was increased. However, pretreatment of the cells with GEP significantly reduced the expression of these proteins in a concentration-dependent manner. These results indicated that the neuroprotective effect of GEP against CORT-induced apoptosis was through inhibition of the ER stress apoptotic pathway.

In addition to these ER chaperone proteins, caspase 12 possesses the capability to activate caspase 9 , subsequently initiating ER stress-induced apoptosis $(54,55)$. In the present study, CORT activated caspases via excessive ER stress cleaving procaspase into active caspase 9 , which in turn activated downstream caspase-cleavage, leading to apoptosis (56). However, GEP pretreatment downregulated the expression of caspase 12, together with caspase 9.

It is known that GEP is a type of polysaccharide, which is a complex molecule with a high molecular weight. The concentration of GEP used in the present study was as high as $1,000 \mu \mathrm{g} / \mathrm{ml}$, which was higher than any physiological concentration. This may be a limitation of the present study, however, three concentrations $(250,500$ and 1,000 $\mu \mathrm{g} / \mathrm{ml})$ of GEP were used to show the neuroprotective effect of GEP. For future clinical application, further investigation is required.

Taken together, the above findings revealed that the neuroprotective effect of GEP occurred through inhibiting the oxidative stress and ER stress-mediated apoptotic pathways.

In conclusion, the results obtained from the in vitro model of depression showed that GEP, which partly reversed the pathological changes induced by CORT, was beneficial in the cytoprotection of neurons, as it may contribute to the attenuation of intracellular ROS and downregulation of the protein expression levels of GRP78, XBP-1, GADD153, caspase 12 and caspase 9 via inhibition of the ER stress-mediated pathway. The results of the present study suggested that the neuroprotective effect of GEP may be one of the available mechanisms underlying its antidepressant-like effects. These results indicate that further investigation of GEP is warranted, which may be a potential candidate in developing antidepressants.

\section{Acknowledgements}

This study was financially supported by the Provincial Natural Science Foundation (grant no. 2010CDB06201).

\section{References}

1. Clark DB, Bukstein O and Cornelius J: Alcohol use disorders in adolescents: Epidemiology, diagnosis, psychosocial interventions, and pharmacological treatment. Paediatr Drugs 4: 493-502, 2002.

2. Dennis CL and Dowswell T: Interventions (other than pharmacological, psychosocial or psychological) for treating antenatal depression. Cochrane Database Syst Rev: CD006795, 2013

3. Zhang K, Zhu Y, Zhu Y, Wu S, Liu H, Zhang W, Xu C, Zhang H, Hayashi T and Tian M: Molecular, Functional, and structural imaging of major depressive disorder. Neurosci Bull 32: 273-285, 2016.

4. World Health Organization (WHO): Depression fact sheet. WHO, Geneva, 2017. http://www.who.int/mediacentre/factsheets/fs369/ en/. Updated February 2017.

5. Jiangsu New Medical College: Chinese Medicine Dictionary. Shanghai Scientific and Technological Press, Shanghai, 1979 (In Chinese).
6. An H, Kim IS, Koppula S, Kim BW, Park PJ, Lim BO, Choi WS, Lee KH and Choi DK: Protective effects of Gastrodia elata Blume on $\mathrm{MPP}^{+}$-induced cytotoxicity in human dopaminergic SH-SY5Y cells. J Ethnopharmacol 130: 290-298, 2010.

7. Jiang G, Hu Y, Liu L, Cai J, Peng C and Li Q: Gastrodin protects against MPP+-induced oxidative stress by up regulates heme oxygenase-1 expression through p38 MAPK/Nrf2 pathway in human dopaminergic cells. Neurochem Int 75: 79-88, 2014

8. Lee OH, Kim KI, Han CK, Kim YC and Hong HD: Effects of acidic polysaccharides from Gastrodia rhizome on systolic blood pressure and serum lipid concentrations in spontaneously hypertensive rats fed a high-fat diet. Int J Mol Sci 13: 698-709, 2012

9. Qiu H, Tang W, Tong X, Ding K and Zuo J: Structure elucidation and sulfated derivatives preparation of two alpha-D-glucans from Gastrodia elata Bl. and their anti-dengue virus bioactivities. Carbohyd Res 342: 2230-2236, 2007

10. Zhou BH,Li XJ,Liu M, Wu Z and Ming Hu X: Antidepressent-like activity of the Gastrodia elata ethanol extract in mice. Fitotorapia 77: 592-594, 2007.

11. Li ZY, Guo Z, Liu YM, Liu XM, Chang Q, Liao YH and Pan RL: Neuroprotective effects of total saikosaponins of Bupleurum yinchowense on corticosterone-induced apoptosis in PC12 cells. J Ethnopharmacol 148: 794-803, 2013

12. Mao QQ, Huang Z, Ip SP, Xian YF and Che CT: Protective effects of piperine against corticosterone-induced neurotoxicity in PC12 cells. Cell Mol Neurobiol 32: 531-537, 2012

13. Zhou YZ, Li X, Gong WX, Tian JS, Gao XX, Gao L, Zhang X, $\mathrm{Du}$ GH and Qin XM: Protective effect of isoliquiritin against corticosterone-induced neurotoxicity in PC12 cells. Food Funct 8: 1235-1244. 2017.

14. Aihara M, Ida I, Yuuki N, Oshima A, Kumano H, Takahashi K, Fukuda M, Oriuchi N, Endo K, Matsuda H and Mikuni M: HPA axis dysfunction in unmedicated major depressive disorder and its normalization by pharmacotherapy correlates with alteration of neural activity in prefrontal cortex and limbic/paralimbic regions. Psychiatry Res 155: 245-256, 2007

15. Murray F, Smith DW and Hutson PH: Chronic low dose corticosterone exposure decreased hippocampal cell proliferation, volume and induced anxiety and depression like behaviours in mice. Eur J Pharmacol 583: 115-127, 2008.

16. Johnson SA, Fournier NM and Kalynchuk LE: Effect of different doses of corticosterone on depression-like behavior and HPA axis responses to a novel stressor. Behav Brain Res 168: 280-288, 2006.

17. Jiang Y, Li Z, Liu Y, Liu X, Chang Q, Liao Y and Pan R: Neuroprotective effect of water extract of Panax ginseng on corticosterone-induced apoptosis in PC12 cells and its underlying molecule mechanisms. J Ethnopharmacol 159: 102-112, 2015.

18. Li M, Zhou J, Qian J, Cheng X, Wu H, Li L, Qian C, Su J, Wu D, Burns L, et al: Target genes involved in corticosterone-induced PC12 cell viability and neurite disorders: A potential molecular mechanism of major depressive disorder. Psychiat Res 235: 206-208, 2016.

19. Zhang H, Liu B, Wu J, Xu C, Tao J, Duan X, Cao Y and Dong J: Icariin inhibits corticosterone-induced apoptosis in hypothalamic neurons via the P13-K/Akt signaling pathway. Mol Med Rep 6: 967-972, 2012.

20. ZhuZ, Yang R,FuX, Wang YQand Wu GC: Astrocyte-conditioned medium protecting hippocampal neurons in primary cultures against corticosterone-induced damages via PI3-K/Akt signal pathway. Brain Res 1114: 1-10, 2006.

21. Liu Y, Shen S, Li Z, Jiang Y, Si J, Chang Q, Liu X and Pan R: Cajaninstilbene acid protects corticosterone-induced injury in PC12 cells by inhibiting oxidative and endoplasmic reticulum stress-mediated apoptosis. Neurochem Int 78: 43-52, 2014.

22. Zhou B, Liang Y, Shen H, et al: Protective effects of polysaccharides of Gastrodia elata blume against corticosterone-induced apoptosis in PC12 cells. J Chinese Med Material: 630-633, 2013 (In Chinese).

23. van Vliet AR and Agostinis P: When under pressure, get closer: PERKing up membrane contact sites during ER stress. Biochem Soc Trans 44: 499-504, 2016.

24. Dias V, Junn E and Mouradian MM: The role of oxidative stress in parkinson's disease. J Parkinson Dis 3: 461-491, 2013.

25. Valko M, Leibfritz D, Moncol J, Cronin MT, Mazur M and Telser J: Free radicals and antioxidants in normal physiological functions and human disease. Int J Biochem Cell Biol 39: 44-84, 2007.

26. Pohanka M: Alzheimer's disease and oxidative stress: A review. Curr Med Chem 21: 356-364, 2014. 
27. James SJ, Cutler P, Melnyk S, Jernigan S, Janak L, Gaylor DW and Neubrander JA: Metabolic biomarkers of increased oxidative stress and impaired methylation capacity in children with autism. Am J Clin Nutr 80: 1611-1617, 2004

28. Kennedy G, Spence VA, McLaren M, Hill A, Underwood C and Belch JJ: Oxidative stress levels are raised in chronic fatigue syndrome and are associated with clinical symptoms. Free Radical Bio Med 39: 584-589, 2005.

29. Jiménez-Fernández S, Gurpegui M, Díaz-Atienza F, Pérez-Costillas L, Gerstenberg M and Correll CU: Oxidative stress and antioxidant parameters in patients with major depressive disorder compared to healthy controls before and after antidepressant treatment: Results from a meta-analysis. J Clin Psychiat 76: 1658-1667, 2015

30. Parellada M, Moreno C, Mac-Dowell K, Leza JC, Giraldez M, Bailón C, Castro C, Miranda-Azpiazu P, Fraguas D and Arango C: Plasma antioxidant capacity is reduced in Asperger syndrome. J Psychiatr Res 46: 394-401, 2012.

31. De la Monte SM and Tong M: Brain metabolic dysfunction at the core of Alzheimer's disease. Biochem Pharmacol 88: 548-559, 2014.

32. Ozcan U, Cao Q, Yilmaz E, Lee AH, Iwakoshi NN, Ozdelen E, Tuncman G, Görgün C, Glimcher LH and Hotamisligil GS: Endoplasmic reticulum stress links obesity, insulin action, and type 2 diabetes. Science 306: 457-461, 2004.

33. Ng TB, He JS, Niu SM, Zhao L, Pi ZF, Shao W and Liu F: A gallic acid derivative and polysaccharides with antioxidative activity from rose (Rosa rugosa) flowers. J Pharm Pharmacol 56: 537-545, 2004

34. Tuvaanjav S, Shuqin H, Komata M, Ma C, Kanamoto T, Nakashima $\mathrm{H}$ and Yoshida T: Isolation and antiviral activity of water-soluble Cynomorium songaricum Rupr. polysaccharides. J Asian Nat Prod Res 18: 159-171, 2016.

35. Banjerdpongchai R, Kongtawelert P, Khantamat O, Srisomsap C, Chokchaichamnankit D, Subhasitanont $\mathrm{P}$ and Svasti J: Mitochondrial and endoplasmic reticulum stress pathways cooperate in zearalenone-induced apoptosis of human leukemic cells. J Hematol Oncol 3: 50, 2010.

36. Banjerdpongchai R, Punyati P, Nakrob A, Pompimon W and Kongtawelert P: 4'-Hydroxycinnamaldehyde from Alpinia galanga (Linn.) induces human leukemic cell apoptosis via mitochondrial and endoplasmic reticulum stress pathways. Asian Pac J Cancer P 12: 593-598, 2011

37. Sardão VA, Oliveira PJ, Holy J, Oliveira CR and Wallace KB Morphological alterations induced by doxorubicin on $\mathrm{H} 9 \mathrm{c} 2$ myoblasts: Nuclear, mitochondrial, and cytoskeletal targets. Cell Biol Toxicol 25: 227-243, 2009.

38. Bernuzzi F, Recalcati S, Alberghini A and Cairo G: Reactive oxygen species-independent apoptosis in doxorubicin-treated H9c2 cardiomyocytes: Role for heme oxygenase-1 down-modulation. Chem Biol Interact 177: 12-20, 2009.

39. Atale N, Gupta S, Yadav UC and Rani V: Cell-death assessment by fluorescent and nonfluorescent cytosolic and nuclear staining techniques. J Microsc 255: 7-19, 2014.

40. McIntosh LJ and Sapolsky RM: Glucocorticoids increase the accumulation of reactive oxygen species and enhance adriamycin-induced toxicity in neuronal culture. Exp Neurol 141: 201-206, 1996
41. McIntosh LJ, Cortopassi KM and Sapolsky RM: Glucocorticoids may alter antioxidant enzyme capacity in the brain: Kainic acid studies. Brain Res 791: 215-222, 1998.

42. Zhou Y, Shu F, Liang X, Chang H, Shi L, Peng X, Zhu J and $\mathrm{Mi}$ M: Ampelopsin induces cell growth inhibition and apoptosis in breast cancer cells through ROS generation and endoplasmic reticulum stress pathway. PLoS One 9: e89021, 2014

43. Lucassen PJ, Müller MB, Holsboer F, Bauer J, Holtrop A, Wouda J, Hoogendijk WJ, De Kloet ER and Swaab DF: Hippocampal apoptosis in major depression is a minor event and absent from subareas at risk for glucocorticoid overexposure. Am J Pathol 158: 453-468, 2001.

44. Rutkowski DT and Kaufman RJ: A trip to the ER: Coping with stress. Trends Cell Biol 14: 20-28, 2004.

45. Shapiro DJ, Livezey M, Yu L, Zheng X and Andruska N: Anticipatory UPR activation: A protective pathway and target in cancer. Trends Endocrinol Metab 27: 731-741, 2016.

46. Kaufman RJ: Stress signaling from the lumen of the endoplasmic reticulum: Coordination of gene transcriptional and translational controls. Gene Dev 13: 1211-1233, 1999.

47. Allagnat F, Christulia F, Ortis F, Pirot P, Lortz S, Lenzen S, Eizirik DL and Cardozo AK: Sustained production of spliced X-box binding protein 1 (XBP1) induces pancreatic beta cell dysfunction and apoptosis. Diabetologia 53: 1120-1130, 2010.

48. Ramji DP and Foka P: CCAAT/enhancer-binding proteins: Structure, function and regulation. Biochem J 365: 561-575, 2002.

49. Huang M, Xu A, Wu X, Zhang Y, Guo Y, Guo F, Pan Z and Kong L: Japanese encephalitis virus induces apoptosis by the IRE1/JNK pathway of ER stress response in BHK-21 cells. Arch Virol 161: 699-703, 2016.

50. Oyadomari S and Mori M: Roles of CHOP/GADD153 in endoplasmic reticulum stress. Cell Death Differ 11: 381-389, 2004.

51. Bertolotti A, Zhang Y, Hendershot LM, Harding HP and Ron D: Dynamic interaction of $\mathrm{BiP}$ and ER stress transducers in the unfolded-protein response. Nat Cell Biol 2: 326-332, 2000.

52. Shen J, Chen X, Hendershot L and Prywes R: ER stress regulation of ATF6 localization by dissociation of BiP/GRP78 binding and unmasking of Golgi localization signals. Dev Cell 3: 99-111, 2002.

53. Zhang Y, Bai C, Lu D, Wu X, Gao L and Zhang W: Endoplasmic reticulum stress and autophagy participate in apoptosis induced by bortezomib in cervical cancer cells. Biotechnol Lett 38: 357-365, 2016.

54. Chandrika BB, Maney SK, Lekshmi SU and Retnabhai ST: Endoplasmic reticulum targeted $\mathrm{Bcl} 2$ confers long term cell survival through phosphorylation of heat shock protein 27. Int J Biochem Cell Biol 42: 1984-1992, 2010.

55. Jiang Y, Lv H, Liao M, Xu X, Huang S, Tan H, Peng T, Zhang Y and Li H: GRP78 counteracts cell death and protein aggregation caused by mutant huntingtin proteins. Neurosci Lett 516: 182-187, 2012.

56. Morishima N, Nakanishi K, Takenouchi $H$, Shibata $T$ and Yasuhiko Y: An endoplasmic reticulum stress-specific caspase cascade in apoptosis. Cytochrome c-independent activation of caspase-9 by caspase-12. J Biol Chem 277: 34287-34294, 2002. 